\title{
56-month clinical performance of Class I and II resin composite restorations
}

\author{
Flavia Bittencourt PAZINATTO' ${ }^{1}$, Ranulfo GIONORDOLI NETO², Linda WANG ${ }^{3}$, José MONDELLI ${ }^{4}$, Rafael Francisco \\ Lia MONDELLI ${ }^{5}$, Maria Fidela de Lima NAVARRO 6
}

\begin{abstract}
1- DDS, MSc, PhD, Assistant Professor, Department of Prosthetic Dentistry, Federal University of Espírito Santo, Vitória, ES, Brazil.
2- DDS, MSc, PhD, Associate Professor, Department of Prosthetic Dentistry, Federal University of Espírito Santo, Vitória, ES, Brazil.

3- DDS, MSc, PhD, Associate Professor, Department of Operative Dentistry, Endodontics and Dental Materials, Bauru School of Dentistry, University of São Paulo, Bauru, SP, Brazil.

4- DDS, MSc, PhD, Full Professor, Department of Operative Dentistry, Endodontics and Dental Materials, Bauru School of Dentistry, University of São Paulo, Bauru, SP, Brazil.

5- DDS, MSc, PhD, Associate Professor, Department of Operative Dentistry, Endodontics and Dental Materials, Bauru School of Dentistry, University of São Paulo, Bauru, SP, Brazil.

6- DDS, MSc, PhD, Full Professor, Department of Operative Dentistry, Endodontics and Dental Materials, Bauru School of Dentistry, University of São Paulo, Bauru, SP, Brazil.
\end{abstract}

Corresponding address: Flavia Bittencourt Pazinatto - Rua Oscar Rodrigues de Oliveira - 336/303 - Jardim da Penha - Vitória - ES - Brasil - e-mail: flaviabpazinatto@yahoo.com.br - Phone/fax: +55-27-33357227

Received: September 10, 2010 - Modification: July 31, 2011 - Accepted: August 31, 2011

\section{ABSTRACT}

\begin{abstract}
bjective: This study evaluated the 56-month clinical performance of Class I and II resin composite restorations. Filtek P60 was compared with Filtek Z250, which are both indicated for posterior restorations but differ in terms of handling characteristics. The null hypothesis tested was that there is no difference in the clinical performance of the two resin composites in posterior teeth. Material and Methods: Thirty-three patients were treated by the same operator, who prepared 48 Class I and 42 Class II cavities, which were restored with Single Bond/Filtek Z250 or Single Bond/Filtek P60 restorative systems. Restorations were evaluated by two independent examiners at baseline and after 56 months, using the modified USPHS criteria. Data were analyzed statistically using Chi-square and Fisher's Exact tests $(\alpha=0.05)$. Results: After 56 months, 25 patients ( 31 Class I and 36 Class II) were analyzed. A 3\% failure rate occurred due to secondary caries and excessive loss of anatomic form for P60. For both restorative systems, there were no significant differences in secondary caries and postoperative sensitivity. However, significant changes were observed with respect to anatomic form, marginal discoloration, and marginal adaptation. Significant decreases in surface texture were observed exclusively for the Z250 restorations. Conclusions: Both restorative systems can be used for posterior restorations and can be expected to perform well in the oral environment.
\end{abstract}

Key words: Clinical trial. Composite resins. Permanent dental restoration.

\section{INTRODUCTION}

Clinical indication of resin composites has increased in posterior restorations over the last decade. This practice is generally accepted by clinicians as a minimally invasive technique ${ }^{10}$ and is requested by patients concerned about esthetics. The resin composite products available on the market vary both in terms of chemical composition and particle filler size, which can alter their behavior in response to the stress and wear caused by masticatory and toothbrushing processes in the oral environment ${ }^{13,24,26}$. These resin systems continue to be technique-sensitive ${ }^{18}$ and do not prevent leakage at the cervical margins as ideally desired ${ }^{6,21}$, leading to secondary caries and postoperative sensitivity ${ }^{6-9,17,22}$.

Although in vitro studies offer important information, such as the mechanical properties, sealing capability, and durability of resinous materials $11-12,21,26,29$, they hardly have a direct correlation with clinical trials. Changes in temperature, the presence of microorganisms, saliva, masticatory stress, and hygiene are 
examples of clinical phenomena that can interfere with the longevity of posterior resin composite

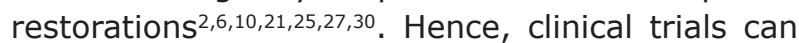
provide useful data regarding the performance of resin composite restorations $\mathrm{s}^{2,14,19,22,23,28,30}$.

Many relatively short-term clinical studies have offered insight into the performance of resin composites on posterior teeth $7,9,19,23,24,30$. Despite the different properties of the resinous materials evaluated in these studies, long-term follow-ups actually provide more information about the survival of these composites in clinical service.

The aim of this study is to report the 56-month performance of two direct resin composites, Filtek Z250 (3M ESPE, St. Paul, MN, USA) and Filtek P60 (3M ESPE), placed in Class I and II cavities. These systems vary in viscosity ${ }^{13}$, but both are indicated for posterior tooth restoration. The null hypothesis tested was that there is no difference between the two composites with respect to cavosurface marginal discoloration, marginal adaptation, secondary caries, anatomic form, surface texture, and postoperative sensitivity.

\section{MATERIAL AND METHODS}

Forty-eight Class I and 42 Class II restorations (45 molars and 45 premolars) were placed in 33 patients (16 males and 17 females, ranging from 18-44 years of age), who were divided into two study groups according to the tested materials (Table 1 ). The mean age was 29 , and the median age was 30 . The restorations were made by the same experienced operator, and the patients included in the study had good oral hygiene and normal occlusion. Each patient received at least two Class I or two Class II restorations of similar types but different restorative materials. Written patient consent was obtained at the commencement of the project, and the protocol was approved by the Human Ethics Committee of Bauru School of Dentistry, University of São Paulo, Brazil. Cavity designs were prepared (restricted to the elimination of carious tissue) using a \#245 carbide bur (Jet;
Beavers Dental Division of Sybron, Morrisburg, ON, Canada), which was changed every 5 preparations, and were finished using hand instruments. All cavity margins were enamel-bordered. The restorative procedures were performed using rubber dam isolation. The dentin in very deep cavities (less than approximately $0.5 \mathrm{~mm}$ of dentin, $\mathrm{n}=4$ teeth) was covered with calcium hydroxide (Dycal; Dentsply Ind. e Com. Ltda., Petrópolis, RJ, Brazil) and resinmodified glass-ionomer cement (Vitrebond; 3M ESPE), whereas that in deep cavities (at least 0.5 $\mathrm{mm}$ of dentin, $\mathrm{n}=7$ teeth) was covered solely with resin-modified glass-ionomer cement.

Enamel and dentin were acid-etched with 35\% phosphoric acid gel (ScotchBond Etchant; 3M ESPE) for 15 s, and Single Bond (SB; 3M ESPE) adhesive system was applied to the dental substrates in accordance with the manufacturer's instructions. Randomization was processed (SPSS-Statistical Package for Social Science, Software Version 12, SPSS Inc., Chicago, IL, USA) so as to allocate the cavities to be restored according to the material (Filtek P60 or Filtek Z250 - Table 1). Paired design was appropriate for detecting differences in performance. Patients and examiners were unaware of this allocation in order to guarantee a doubleblind study.

The materials used in this study are indicated in Figure 1. Resin composite placement followed the incremental technique (up to $2 \mathrm{~mm}$-thick layers) using a flat-faced condenser. Each resin composite layer was light-cured for $20 \mathrm{~s}$. A halogen light-curing unit (XL 3000; 3M ESPE) with the curing intensity set at $600 \mathrm{~mW} / \mathrm{cm}^{2}$ was used for light-curing. After restorative procedures, a post-occlusal adjustment was performed using carbon paper and burs (Jet; Beavers Dental Division of Sybron).

Finishing and polishing of the restorations took place one week later, using multi-laminated carbide burs (Jet; Beavers Dental Division of Sybron), abrasive points (KG Sorensen, Barueri, SP, Brazil), polishing points (Enhance; Dentsply Ind. e Com. Ltda., Petrópolis, RJ, Brazil), and diamond paste (Kota Ind. e Com. Ltda., São Paulo, SP, Brazil).

Table 1- Number of restorations evaluated at baseline and after 56 months by tooth location and extension (class) into different study groups

\begin{tabular}{|c|c|c|c|c|c|}
\hline \multirow[t]{2}{*}{ Groups } & \multirow[t]{2}{*}{$\begin{array}{c}\text { Number of } \\
\text { restorations } \\
\text { baseline/56 months }\end{array}$} & \multicolumn{2}{|c|}{$\begin{array}{l}\text { Tooth } \\
\text { baseline/ } \\
56 \text { months }\end{array}$} & \multicolumn{2}{|c|}{$\begin{array}{c}\text { Class } \\
\text { baseline/ } \\
56 \text { months }\end{array}$} \\
\hline & & Premolars & Molars & I & II \\
\hline $1(\mathrm{SB}+\mathrm{Z250})$ & $47 / 33$ & $22 / 19$ & $24 / 14$ & $30 / 19$ & $17 / 14$ \\
\hline $2(\mathrm{SB}+\mathrm{P} 60)$ & $43 / 34$ & $23 / 19$ & $21 / 15$ & $18 / 12$ & $25 / 22$ \\
\hline Total & $90 / 67$ & $45 / 38$ & $45 / 29$ & $48 / 31$ & $42 / 36$ \\
\hline
\end{tabular}

SB=Single Bond; Z250=Filtek Z250; P60=Filtek P60 
Each restoration was evaluated by two independent and calibrated clinicians utilizing the modified United States Public Health Service (USPHS) criteria ${ }^{1}$. Evaluation criteria included the following: cavosurface marginal discoloration, secondary caries, anatomic form, surface texture, marginal adaptation, and postoperative sensitivity (Figure 2 ). Bitewing radiographs were only taken when they were appropriate for diagnostic examination (as opposed to the baseline data).

The inter-examiner kappa index was 0.93 for the 56-month evaluation. When disagreement occurred during evaluation, a consensus was obtained among the examiners. The data was statistically analyzed by means of the Chi-square and Fisher Exact tests at a confidence level of $95 \%$.

\section{RESULTS}

After 56 months, 25 patients with a total of 67 restorations ( 31 Class I and 36 Class II) were analyzed. Eight patients were dropped from the study because they had moved out of town ( 3 patients) or could not be reached for other reasons (5 patients). Of the total patients at recall, one patient had extracted one tooth (Class I molar, Filtek Z250) and had submitted another to endodontic treatment (Class I molar, Filtek P60) due to periodontal problems. The evaluation rate according to the modified USPHS scores at 56 months is

\begin{tabular}{|c|c|c|c|}
\hline Materials & Composition & Manufacturers & Batch number \\
\hline Single Bond & $\begin{array}{c}\text { Bis-GMA, HEMA, dimethacrylates, polyalkenoic } \\
\text { acid, copolymer, initiator, water, ethanol }\end{array}$ & $\begin{array}{c}\text { 3M ESPE, St. Paul, MN, } \\
\text { USA }\end{array}$ & $8 \mathrm{BX}$ \\
\hline Filtek Z250 & Bis-GMA, UDMA, Bis-EMA, filler $(0.01-3.5 \mu \mathrm{m})$ & $\begin{array}{c}\text { 3M ESPE, St. Paul, MN, } \\
\text { USA }\end{array}$ & 12090 \\
\hline Filtek P60 & Bis-GMA, UDMA, Bis-EMA, filler $(0.01-3.5 \mu \mathrm{m})$ & $\begin{array}{c}\text { 3M ESPE, St. Paul, MN, } \\
\text { USA }\end{array}$ & 9099 \\
\hline
\end{tabular}

Bis-GMA=Bisfenol glycidil methacrylate

HEMA=2- Hidroxi-ethyl-methacrylate

UDMA=Urethane dimethylmetacrylate

Bis-EMA=Ethoxylate-bisfenol glycidil methacrylate

Figure 1- Description of the adhesive system and resin composites used in this study

\begin{tabular}{|c|c|}
\hline Cavosurface marginal discoloration & $\begin{array}{l}\text { Alfa }(A) \text { : No penetration of staining at the marginal interface } \\
\text { Bravo (B): Penetration along the margin, but not in a pulpal direction } \\
\text { Charlie (C): Penetration at the margin to the level of dentin or in a pulpal direction }\end{array}$ \\
\hline Secondary caries & $\begin{array}{l}\text { Alfa (A): No evidence of caries at the margin } \\
\text { Charlie (C): Evidence of caries at the margin }\end{array}$ \\
\hline Anatomic form & $\begin{array}{l}\text { Alfa (A): Restoration continuous with tooth } \\
\text { Bravo (B): Restorations discontinuous with tooth, but without exposure of the } \\
\text { dentin or base } \\
\text { Charlie (C): Material missing, exposing dentin or base }\end{array}$ \\
\hline Surface texture & $\begin{array}{l}\text { Alfa (A): Surface is as smooth as the surrounding enamel } \\
\text { Bravo (B): Surface is rougher than surrounding enamel } \\
\text { Charlie (C): Surface is very rough avoiding continuous movement of the explorer }\end{array}$ \\
\hline Marginal adaptation & $\begin{array}{l}\text { Alfa (A): No visible evidence of crevice along margin can be detected by the } \\
\text { explorer } \\
\text { Bravo (B): Crevice detected by the explorer, but without exposure of the dentin } \\
\text { or base } \\
\text { Charlie (C): Dentin or base exposed } \\
\text { Delta (D): The restoration is mobile or fractured }\end{array}$ \\
\hline Postoperative sensitivity & $\begin{array}{l}\text { Alfa }(A) \text { : Not present } \\
\text { Bravo (B): Sensitive but diminishing in intensity } \\
\text { Charlie (C): Spontaneous sensitivity }\end{array}$ \\
\hline
\end{tabular}

Figure 2- Modified United States Public Health Service (USPHS) criteria and parameters used for the clinical evaluation of the restorations 
Table 2- Summary of frequencies of United States Public Health Service (USPHS) criteria scores (\%) at baseline and 56 months

\begin{tabular}{ccccccccc}
\hline Groups & Recall & $\mathbf{n}$ & $\begin{array}{c}\text { Cavosurface } \\
\text { marginal } \\
\text { discoloration }\end{array}$ & $\begin{array}{c}\text { Secondary } \\
\text { caries }\end{array}$ & $\begin{array}{c}\text { Anatomic } \\
\text { form }\end{array}$ & $\begin{array}{c}\text { Surface } \\
\text { texture }\end{array}$ & $\begin{array}{c}\text { Marginal } \\
\text { adaptation }\end{array}$ & $\begin{array}{c}\text { Postoperative } \\
\text { sensitivity }\end{array}$ \\
\hline (Z250) & Baseline & 100 & A 100 & A 100 & A 100 & A 100 & A 100 & A 100 \\
& & & B 0 & C 0 & B 0 & B 0 & B 0 & B 0 \\
& & & C 0 & & C 0 & C 0 & C 0 & C 0 \\
& 56 months & 84 & A 79 & A 100 & A 58 & A 88 & A 76 & A 100 \\
\hline & & B 21 & C 0 & B 42 & B 12 & B 24 & B 0 \\
(P60) & Baseline & 100 & A 100 & A 100 & A 100 & A 100 & A 100 & A 100 \\
& & & B 0 & C 0 & B 0 & B 0 & B 0 & B 0 \\
\hline & & C 0 & & C 0 & C 0 & C 0 & C 0 \\
& & & A 71 & A 97 & A 59 & A 91 & A 68 & A 100 \\
\hline
\end{tabular}

Table 3- Statistical values of the comparisons between the performances of the materials

\begin{tabular}{cccc}
\hline & $\begin{array}{c}\text { Z250 } \\
\text { (baseline x 56-months) }\end{array}$ & $\begin{array}{c}\text { P60 } \\
\text { (baseline x 56-months) }\end{array}$ & Z250 x P60 \\
\hline Cavosurface marginal discoloration & 0.002 & $<0.001$ & 0.576 \\
Secondary caries & 1.000 & 0.430 & 1.000 \\
Anatomic form & $<0.001$ & $<0.001$ & 0.592 \\
Surface texture & 0.029 & 0.076 & 0.705 \\
Marginal adaptation & $<0.001$ & $<0.001$ & 0.590 \\
Postoperative sensitivity & 1.000 & 1.000 & 1.00 \\
\hline
\end{tabular}

$\mathrm{P}<0.05$ are statistically significant

shown in Table 2 and Table 3.

Comparing the two evaluation periods for Filtek Z250, A score rates significantly decreased for cavosurface marginal discoloration $(p<0.001)$, anatomic form $(p<0.001)$, surface texture $(p=0.029)$, and marginal adaptation $(p<0.001)$ criteria. In Filtek Z250 group, no C score rates were noted. An evaluation of the Filtek P60 group demonstrated a significant decrease in A score rates for cavosurface marginal discoloration $(p<0.001)$, anatomic form $(p<0.001)$, and marginal adaptation $(p<0.001)$. Filtek $Z 250$ group did not present any secondary caries $(p=1.00)$, whereas in Filtek P60 group, one restoration failed due to secondary caries (Class II premolar) and another as a result of unacceptable anatomic form (Class II premolar) $(p=0.430)$. No failure occurred among the Class I restorations. The failure rate for Class II restorations amounted to $6 \%$. In both groups, none of the patients reported postoperative sensitivity after 56 months of restoration placement $(p=1.00)$.
At 56 months, no differences among modified USPHS criteria were found between the $\mathbf{Z 2 5 0}$ and P60 groups $(p<0.05)$.

\section{DISCUSSION}

The number of patients attending recalls is relevant to obtaining reliable data regarding the performance of the restorations in clinical trials. In this study, $76 \%$ of the patients attended the 56 -month recall, and $74 \%$ of the total restorations evaluated at baseline were re-evaluated in this period. All patients received notification letters and/ or phone calls, in which the 56-month appointment evaluation was conducted. Unfortunately, eight patients could not be contacted.

The results of this study indicate that resin composite restorations can work well in posterior teeth, as the failure rate for the evaluated restorations (67) was very low (3\%). Only one patient suffered from two failed restorations due 
to secondary caries and excessive loss of anatomic form. This most likely occurred because the patient changed his hygiene habits, allowing bacteria to accumulate and leading to resin composite degradation ${ }^{27}$. Another patient was submitted to endodontic treatment and tooth extraction due to the exposed root furcation of the restored molars, but not due to a direct failure of the restoration.

The longevity of restorations is dependent on many factors, including the materials and techniques used, patient compliance with oral hygiene, and patient's susceptibility to caries ${ }^{4}$. Most of the patients evaluated presented good hygiene and had no primary caries formation or periodontal problems, leading to a low rate of restoration failure.

None of the patients reported postoperative sensitivity after 56 months of evaluation $(p=0.001)$. The lack of sensitivity may be the result of a calcium hydroxide liner and/or resin-modified glassionomer liner in deep and very deep cavities. The use of liners protects the pulpal-dentin complex, avoiding or decreasing the possibility of thermal/ electric stimuli, minimizing hydrodynamic fluid movements, and also leading to respiratory dentin formation in very deep cavities ${ }^{5}$. The Single Bond adhesive system used is known to behave quite well in adhesion procedures, particularly on enamel${ }^{7}$, and could minimize external fluid/ bacteria penetration at the adhesive interface? In addition, the incremental insertion technique of resin composites may influence the absence of postoperative sensitivity, as this technique results in an extremely limited gap formation between the resin-dentin interface ${ }^{15}$. Some authors ${ }^{19}$ have correlated postoperative sensitivity with the choice of restorative technique and adhesive system. If liners were not used, the results could have been different. Thus, the success expressed in the absence of postoperative sensitivity over 56 months should be interpreted with caution due to the limitations of the study.

On the other hand, for both materials, A score rates of cavosurface marginal discoloration decreased significantly from the baseline to the 56 -month recall. B score rates of $29 \%$ and $22 \%$ for Filtek Z250 and Filtek P60, respectively, were present at the 56-month recall and may be explained by food pigmentation. The cavosurface marginal discoloration may be related as a function of adhesive system thickness and composition ${ }^{17}$ as well, rather than only due to resin composite. Most likely, the thickness and chemical composition of the adhesive at the tooth/restoration interface may suffer degradation, consequently resulting in staining by oral fluid penetration over the past 56 months, influencing these results.

Deficiencies in marginal adaptation may not only be due to gap formation, but to an excess of adhesive system ${ }^{14}$ or resin composite, impairing the adequate adaptation up to the cavosurface margin, regardless of finishing procedures. Moreover, the thin sections of adhesive system or resin composite overhangs may not resist abrasion at the tooth/ restoration interface in stressed areas and may lead to a poor marginal adaptation ${ }^{3}$.

The anatomic form is sustained by the capacity of the resin composites to resist to the wear promoted by food and liquids presented in the diet during the masticatory process ${ }^{17,26}$. The chemical composition, type, and amount of filler can alter the wear on restorations ${ }^{26}$. Furthermore, the chemical composition of the materials can influence their viscosities and handling characteristics. The viscosity of composite resins is based on a multifactorial determination: type and ratio of resin matrix components, the size and shape of the inorganic filler, the filler content, and, in particular, the interlocking between filler particles and interfacial interactions between filler particles and the resin matrix ${ }^{13,26}$. However, despite the differences in the viscosities and handling of Filtek Z250 and Filtek P60, there are few differences in the filler characteristics and chemical composition of the two resin composites studied, according to the 3M ESPE technical profile. These similar characteristics may explain the relatively comparable results observed in this study after a 56-month evaluation of both restorative systems. A lack of long-term clinical data on the studied materials exists, but several short-term studies have related good performance to certain components similar to those found in Z100 (3M ESPE) ${ }^{28}$. Despite the excellent short-term clinical performance of Filtek P60 that some authors determined ${ }^{14}$ and that of Filtek Z250 that others found ${ }^{28}$, the anatomic form suffered degradation over time, as demonstrated by the reduction in A score and the increase in B score in the present study. Surface texture was expected to be altered in both restorative systems, such as anatomic form, after 56 months due to organic matrix abrasion, with/without appearance of bubbles enclosed within the resin composite. These bubbles were only observed using a sharp explorer, and none of the patients complained about this. In accordance with a 7-year study ${ }^{24}$, few clinical alterations were observed in the resin composite surface texture.

The use of posterior adhesive restorations can permit a more "conservative" approach due to cavity preparation. Apart from esthetics, this study demonstrated that resin composites may be a durable alternative for restoration of posterior teeth, as suggested by other authors ${ }^{16,20}$. However, the durability of composite restorations in the oral environment can also be affected by the sensitivity 
of the technique, the operator variability, and the patient's oral hygiene and habits.

\section{CONCLUSIONS}

Based on the results of this study, it seems reasonable to conclude that the two restorative systems demonstrated good clinical performance after 56 months in cavities with enamel-bordered margins and in low-risk patients. Thus, the null hypothesis was accepted. No failure occurred among the Class I restorations; however, the failure rate for Class II restorations amounted to $6 \%$. Although there was evident degradation of surface and marginal characteristics when compared with the baseline data, these changes do not compromise the permanency of restorations in an oral environment. Subsequent follow-ups are required in order to determine the durability of these systems and provide more information regarding the behavior of the changes observed in this study.

\section{ACKNOWLEDGEMENTS}

This work was partially supported by Coordenação de Aperfeiçoamento de Pessoal de Nível Superior (CAPES).

\section{REFERENCES}

1- Bayne SC, Schmalz G. Reprinting the classic article on USPHS evaluation methods for measuring the clinical research performance of restorative materials. Clin Oral Investig. 2005;9:209-14.

2- Bernardo M, Luis $H$, Martin MD, Leroux BG, Rue T, Leitão J, et al. Survival and reasons for failure of amalgam versus composite posterior restorations placed in a randomized clinical trial. J Am Dent Assoc. 2007;138:775-83.

3- Burgess JO, Gallo JR, Ripps AH, Walker RS, Ireland EJ. Clinical evaluation of four Class 5 restorative materials: 3-year recall. Am J Dent. 2004;17:147-50.

4- Burke FJ, Wilson NH, Cheung SW, Mjör IA. Influence of patient factors on age of restorations at failure and reasons for their placement and replacement. J Dent. 2001;29:317-24.

5- Costa CA, Giro EM, Nascimento AB, Teixeira HM, Hebling J. Short-term evaluation of the pulpo-dentin complex response to a resin-modified glass-ionomer cement and a bonding agent applied in deep cavities. Dent Mater. 2003;19:739-46.

6- Cunha Mello FS, Feilzer AJ, De Gee AJ, Davidson CL. Sealing ability of eight resin bonding systems in a Class II restoration after mechanical fatiguing. Dent Mater. 1997;13:372-6.

7- De Munck J, Van Meerbeek B, Yoshida Y, Inoue S, Vargas $M$, Suzuki K, et al. Four-year water degradation of total-etch adhesives bonded to dentin. J Dent Res. 2003;82:136-40.

8- Dietschi DA, Holz J. A clinical trial of four light-curing posterior composite restorations: two-year report. Quintessence Int. 1990;21:965-75.

9- Ernst CP, Buhtz C, Rissing C, Willershausen B. Clinical performance of resin composite restoration after 2 years. Compend Cont Educ Dent. 2002;23:711-22.
10- Fernandez EM, Martin JA, Angel PM, Mjör IA, Gordan VV, Moncada GA. Survival rate of sealed, refurbished and repaired defective restorations: 4-year follow-up. Braz Dent J. 2011;22:134-9.

11- Hashimoto M, Ohno H, Sano H, Kaga M, Oguchi H. Degradation patterns of different adhesives and bonding procedures. J Biomed Mater Res B Appl Biomater. 2003;66:324-30.

12- Labella R, Lambrechts P, Van Meerbeek B, Vanherle G. Polymerization shrinkage and elasticity of flowable composites and filled adhesives. Dent Mater. 1999;15:128-37.

13- Lee IB, Son HH, Um CM. Rheologic properties of flowable, conventional hybrid, and condensable composite resins. Dent Mater. 2003;19:298-307.

14- Leirskar J, Henaug T, Thorensen NR, Nordbo H, Von Der Fehr FR. Clinical performance of indirect composite resin inlays/onlays in a dental school: observations up to 34 months. Acta Odontol Scand. 1999;57:216-20.

15- Lopes GC, Baratieri LN, Monteiro S Jr, Vieira LC. Effect of posterior resin composite placement technique on the resin-dentin interface formed in vivo. Quintessence Int. 2004;35:156-61.

16- Lopes LG, Cefaly DF, Franco EB, Mondelli RF, Lauris JR, Navarro MF. Clinical evaluation of two "packable" posterior composite resins: two-year results. Clin Oral Investig. 2003;7:123-8.

17- Mair LH, Vowles RH, Cunningham J, Williams DF. The clinical wear of three posterior composites. Br Dent J. 1990;169:355-60. 18- Miyazaki M, Onose $\mathrm{H}$, Moore BK. Effect of operator variability on dentin bond strength of two-step bonding systems. Am J Dent. 2000;13:101-4.

19- Opdam NJ, Feilzer AJ, Roeters JJ, Smale I. Class I occlusal composite resin restorations: in vivo post-operative sensitivity, wall adaptation, and microleakage. Am J Dent. 1998;11:229-34. 20- Pallesen U, Qvist V. Composite fillings and inlays. An 11-year evaluation. Clin Oral Investig. 2003;7:71-9.

21- Pazinatto FB, Campos BB, Costa LC, Atta MT. Effect of the number of thermocycles on microleakage of resin composite restorations. Pesqui Odontol Bras. 2003;17:337-41.

22- Raskin A, Michotte-Theall B, Vreven J, Wilson NH. Clinical evaluation of a posterior composite 10-year report. J Dent. 1999;27:13-9.

23- Sachdeo A, Gray GB, Sulieman MA, Jagger DC. Comparison of wear and clinical performance between amalgam, composite and open sandwich restorations: 2-year results. Eur J Prosthodont Restor Dent. 2004;12:15-20.

24- Türkün LS, Aktener BO, Ates M. Clinical evaluation of different posterior resin composite materials: a 7-year report. Quintessence Int. 2003;34:418-26.

25- Voltarelli FR, Santos-Daroz CB, Alves MC, Cavalcanti AN, Marchi GM. Effect of chemical degradation followed by toothbrushing on the surface roughness of restorative composites. J Appl Oral Sci. 2010;18:585-90.

26- Wang L, Garcia FC, Araújo PA, Franco EB, Mondelli RFL. Wear resistance of packable resin composites after simulated toothbrushing test. J Esthet Rest Dent. 2004;16:303-15.

27- Willershausen B, Callaway A, Ernst CP, Stender E. The influence of oral bacteria on the surfaces of resin-based dental restorative materials: an in vitro study. Int Dent J. 1999;49:231-9.

28- Wilson MA, Cowan AJ, Randall RC, Crisp RJ, Wilson NH. A practice-based, randomized, controlled clinical trial of a new resin composite restorative: one-year results. Oper Dent. 2002;27:4239.

29- Yap AU, Teoh SH. Comparison of flexural properties of composite restoratives using the ISO and mini-flexural tests. J Oral Rehabil. 2003;30:171-7.

30- Yip KH, Poon BK, Chu FC, Poon EC, Kong FY, Smales RJ. Clinical evaluation of packable and conventional hybrid resin-based composites for posterior restorations in permanent teeth: results at 12 months. J Am Dent Assoc. 2003;134:1581-9. 